\title{
Improving Cell Penetration of Gold Nanorods by Using an Amphipathic Arginine Rich Peptide
}

\author{
Ana L Riveros ${ }^{1,2}$ \\ Cynthia Eggeling (iD ${ }^{3}$ \\ Sebastián Riquelme \\ Carolina Adura' \\ Carmen López-Iglesias ${ }^{4}$ \\ Fanny Guzmán ${ }^{3}$ \\ Eyleen Araya ${ }^{5}$ \\ Mario Almada ${ }^{6}$ \\ Josué Juárez ${ }^{6}$ \\ Miguel A Valdez $\mathbb{1 D}^{6}$ \\ Ignacio A Fuentevilla $\mathbb{D}^{1,2,7}$ \\ Olga López ${ }^{8}$ \\ Marcelo J Kogan (iD) 1,2 \\ 'Departamento de Química Farmacológica \\ y Toxicológica, Facultad de Ciencias Químicas \\ y Farmacéuticas, Universidad de Chile, Santiago, \\ Chile; ${ }^{2}$ Advanced Center for Chronic Diseases \\ (ACCDiS), Universidad de Chile, Santiago, Chile; \\ ${ }^{3}$ Núcleo de Biotecnología Curauma (NBC), \\ Universidad Católica de Valparaíso, Valparaíso, \\ Chile; ${ }^{4}$ Microscopy CORE Lab, The Maastricht \\ Multimodal Molecular Imaging Institute FHML, \\ Maastricht University, Maastrich, Netherlands; \\ ${ }^{5}$ Departamento de Ciencias Quimicas, Facultad \\ de Ciencias Exactas, Universidad Andres Bello, \\ Santiago, Chile; ${ }^{6}$ Departamento de Física, \\ Universidad de Sonora, Hermosillo, Sonora, \\ México; ${ }^{7}$ Laboratorio de Investigación en \\ nutrición funcional (LINF), Instituto de Nutrición \\ y Tecnología de los alimentos (INTA), Universidad \\ de Chile, Santiago, Chile; ${ }^{8}$ Department \\ Surfactants and Nanobiotechnology, Institute for \\ advanced chemistry of Catalonia, Consejo \\ Superior de Investigaciones Científicas (IQAC- \\ CSIC), Barcelona, Spain
}

Correspondence: Marcelo J Kogan; Ana L Riveros

Department of Pharmacological and Toxicological Chemistry, University of Chile, Santos Dumont 964 , Independencia, Santiago 8380494, Chile Tel +56 229782897; +56229782918

Email mkogan@ciq.uchile.cl;

ariveros@uchile.cl
This article was published in the following Dove Press journal:

International Journal of Nanomedicine

\author{
(1)
}

\begin{abstract}
Introduction: Gold nanorods are highly reactive, have a large surface-to-volume ratio, and can be functionalized with biomolecules. Gold nanorods can absorb infrared electromagnetic radiation, which is subsequently dispersed as local heat. Gold nanoparticles can be used as powerful tools for the diagnosis and therapy of different diseases. To improve the biological barrier permeation of nanoparticles with low cytotoxicity, in this study, we conjugated gold nanorods with cell-penetrating peptides (oligoarginines) and with the amphipathic peptide CLPFFD.
\end{abstract}

Methods: We studied the interaction of the functionalized gold nanorods with biological membrane models (liposomes) by dynamic light scattering, transmission electron microscopy and the Langmuir balance. Furthermore, we evaluated the effects on cell viability and permeability with an MTS assay and TEM.

Results and Discussion: The interaction study by DLS, the Langmuir balance and cryoTEM support that GNR-Arg ${ }_{7}$ CLPFFD enhances the interactions between GNRs and biological membranes. In addition, cells treated with GNR-Arg ${ }_{7}$ CLPFFD internalized $80 \%$ more nanoparticles than cells treated with GNR alone and did not induce cell damage.

Conclusion: Our results indicate that incorporation of an amphipathic sequence into oligoarginines for the functionalization of gold nanorods enhances biological membrane nanoparticle interactions and nanoparticle cell permeability with respect to nanorods functionalized with oligoarginine. Overall, functionalized gold nanorods with amphipathic arginine rich peptides might be candidates for improving drug delivery by facilitating biological barrier permeation.

Keywords: gold nanorods, cell-penetrating peptides, amphipathic arginine rich peptide, liposome, biological barrier permeation

\section{Introduction}

Global progress in nanotechnology has led to notable developments in nanomedicine, including new diagnostic systems, drug delivery methods, and a variety of disease treatments. ${ }^{1-6}$ One such advancement is represented by gold nanoparticles, which have a large surface-to-size ratio and are highly reactive. ${ }^{7,8}$ These properties allow gold nanoparticle functionalization with synthetic molecules or biomolecules (eg, antibodies, polymers, drugs, DNA, RNA, and peptides), in addition to facilitating biological barrier permeation and, consequently, access to different sites of interest. $^{2,3,9-11}$ Gold nanoparticles can also absorb and disperse electromagnetic radiation as local heat, ${ }^{12,13}$ specifically by absorbing visible (ie, nanospheres) and near-infrared (ie, nanorods, nanoshells) radiation, depending on their shape and size. ${ }^{14-16}$ Near-infrared radiation can be absorbed by gold nanorods (GNRs), a type 
of gold nanoparticle that may have applications in photothermal therapy for cancer and neurodegenerative disorders.

Photothermal therapy generates local damage to cancer cells and the disaggregation of toxic protein aggregates involved in neurodegenerative diseases, such as Alzheimer's disease. ${ }^{17,18}$ Gold nanospheres and GNRs have been successfully functionalized with the amphipathic peptide CLPFFD, which recognizes toxic aggregates of amyloid- $\beta$ (TAA $\beta$ ), ${ }^{19-21}$ a protein that induces the formation of amyloid fibrils in plaques present in Alzheimer's disease. ${ }^{22,23}$ Moreover, the peptide CLPFFD, due to its amphipathic character, increases the interactions with the cell membrane, improving cell penetration of the nanoparticles. Therefore, the generation of new gold nanoparticle therapies for central nervous system diseases fundamentally relies on improving blood-brain barrier penetration, with research particularly being needed regarding the internalization or biophysical interactions of gold nanoparticles with biological barriers and cell membranes.

On the other hand, cell-penetrating peptides (CPPs) have promising traits that lend to their possible use as a drug delivery vector, ${ }^{24-26}$ including low toxicity, high efficiency for different cell lines and easy adaptation to drug administration systems. CPPs are short peptide sequences that comprise a wide diversity of structures. They can be classified into three groups depending on their physicochemical properties: cationic, amphipathic or hydrophobic. The majority of CPPs have a net positive charge $(83 \%)$ due to the presence of a high number of basic residues in their sequence (arginine or lysine). A net positive charge promotes interactions with negatively charged membranes, which gives them cellular internalization capacities; ${ }^{27}$ nevertheless, the cellular uptake mechanism has yet to be revealed. ${ }^{28,29}$ Therefore, CPPs may enhance the crossing of gold nanoparticles through the blood-brain barrier. In this regard, some studies have reported the use of CPPs on the surface of nanoparticles for brain drug delivery, ${ }^{30,31} \mathrm{eg}$, the use of gold nanoparticles functionalized with the cell-penetrating peptide TAT, to increase doxorubicin delivery to brain metastatic breast cancer cells. $^{32}$ One kind of CPP is the arginine sequence of peptides as oligoarginines. However, there are few studies related to the functionalization of GNRs with oligoarginines. One example is the functionalization of GNRs with a cysteine-octoarginine peptide to take up activated macrophages in autoimmune and inflammatory diseases for photothermolysis. $^{33}$
Considering the importance of the primary interaction between GNRs and the cell membrane for the cell internalization process, in this work, we conjugated GNRs to a sequence that contains an oligoarginine and the amphipathic peptide sequence CLPFFD to evaluate whether the first interaction with the membrane is favored and subsequently leads to cell internalization. The positive charges given by the arginines would promote an interaction with the negatively charged membranes, while the amphipathic CLPFFD peptide sequence enables interactions with the amphipathic phospholipid membrane.

The oligoarginine sequence was conjugated with the amphipathic peptide CLPFFD ${ }^{20,23,34}$ to form the construct RRRRRRRCLPFFD. To promote anchoring onto the surface of the gold nanoparticles, the cysteine residue was maintained between the two parts of the construct (ie, $\operatorname{Arg}_{7}$ and LPFFD). These peptides showed a "Y shape" on the GNR surface, with the cysteine residue located at the lower end of the "Y," acting as an anchor point for peptide chemisorption onto the GNR surface. ${ }^{35}$ In turn, $\operatorname{Arg}_{7}$, with LPFFD, were located on the upper portion of the "Y", a location that would allow for each moiety to interact with the biological barriers. ${ }^{23}$

To study the differential effects of the functionalized sequence components (ie, CPP, the recognition portion, and the cysteine residue) on the internalization process, GNRs were conjugated with the peptides CRRRRRRR ( $\left.\mathrm{CArg}_{7}\right)$, RRRRRRRCLPFFD ( $\operatorname{Arg}_{7} \mathrm{CLPFFD}$ ), and CLPFFD. Cell internalization of the conjugates was determined in human neuroblastoma SH-SY5Y cells. The interactions of the nanoconjugates were monitored using soybean phosphatidylcholine unilamellar lipid vesicles and SH-SY5Y cells. However, this study did not focus on the cellular internalization mechanism. Therefore, the $\operatorname{Arg}_{7} \mathrm{CLPFFD}$ conjugate increased liposome interactions and SH-SY5Y cellular uptake without affecting cell viability.

\section{Materials and Methods}

\section{Preparation of the Liposomes}

Soybean PC (Lipoid S100; PC > 94\%) was purchased from lipoid $\mathrm{GmbH}$ (Germany). Lipoid S100 contains 94\% PC, and the typical composition related to total fatty acids is approximately $15 \%$ palmitic acid (C16), $4 \%$ stearic acid (C18), 7\% oleic acid (18:1), 70\% linoleic acid (18:2), and 6\% linolenic acid (18:3).

Liposomes were obtained by hydration (using Milli.Q water) of the lipidic film formed by rotary evaporation of 
a chloroform lipid mixture. To obtain a defined size (200 $\mathrm{nm}$ ), the vesicles were extruded by a 10-fold passage through $800-200 \mathrm{~nm}$ polycarbonate membranes. ${ }^{36}$ The systems were characterized by dynamic light scattering (DLS), small angle X-ray scattering (SAXS) and cryotransmission electron microscopy (Cryo-TEM) and maintained under refrigeration $\left(4^{\circ} \mathrm{C}\right)$ until use.

\section{Synthesis and Conjugation of Gold Nanorods with the Peptides CLPFFD, $\mathrm{CArg}_{7}, \mathrm{Arg}_{7} \mathrm{CLPFFD}$}

The peptides were synthesized following protocols previously described in reference. ${ }^{17}$ The peptides CLPFFD, CRRRRRRR ( $\left.\mathrm{CArg}_{7}\right)$ and RRRRRRRCLPFFD ( $\mathrm{Arg}_{7} \mathrm{CL}$ PFFD) were synthesized using a fluorenylmethyloxycarbonyl (Fmoc) strategy and solid-phase synthesis. With this strategy, the peptides were obtained in a sequential way through the protecting groups Fmoc/tBu. For this procedure, polypropylene syringes equipped with polypropylene porous discs and a polymeric or Rink amide type resin support (substitution $0.72 \mathrm{mmol} / \mathrm{g}$ of resin) and 2- chlorotrityl ( 0.15 y $0.3 \mathrm{mmol} / \mathrm{g}$ of resin) were used.

GNRs were synthesized and conjugated following protocols described previously in reference. ${ }^{21}$ Briefly, GNRs were synthesized using the seed-mediated approach. First, a seed solution was prepared by reduction of 0.01 $\mathrm{M} \mathrm{HAuCl}_{4}$ in a solution of $0.1 \mathrm{M} \mathrm{CTAB}$ with 0.01 $\mathrm{M}$ sodium borohydride. Next, $0.1 \mathrm{M}$ ascorbic acid was added to a growth solution with $0.01 \mathrm{M} \mathrm{AgNO}_{3}, 0.1$ $\mathrm{M} \mathrm{CTAB}$, and $0.01 \mathrm{M} \mathrm{HAuCl}_{4}$. Then, $0.1 \mathrm{M} \mathrm{HCl}$ and the seed solution were added to the growth solution. The mixture was allowed to react for $10 \mathrm{~min}$ at $27{ }^{\circ} \mathrm{C}$ before centrifugation at $7030 \mathrm{~g}$ for $15 \mathrm{~min}$.

For conjugation of the peptides to the GNRs, these were synthesized as described above, and after the centrifugation step, the pellets to prepare GNR-CLPFFD were suspended in an aqueous peptide solution of $0.25 \mathrm{mg} / \mathrm{mL}$, and the mixture was allowed to react for $72 \mathrm{~h}$ at $27^{\circ} \mathrm{C}$ to form a complete layer of peptide replacing CTAB from the nanomaterial surface. Finally, before the experiments, GNR-peptide and GNR-CTAB were centrifuged at $1520 \mathrm{~g}$ for $60 \mathrm{~min}$.

Finally, the GNRs and GNR-peptide were characterized by Vis-NIR spectrophotometry, transmission electron microscopy (TEM), and dynamic light scattering (DLS). The absorption spectra were recorded at room temperature with a Perkin Elmer Lambda 25 UV/VIS spectrophotometer. The samples were prepared over formvar carbon- coated copper microgrids and observed with a JEOL JEM-1010 transmission electron microscope.

\section{Calculation of the Gold Nanorod Concentration and Number of Peptide Molecules per Gold Nanorod}

An aliquot of a known volume of GNRs solution was lyophilized, and the gold content was determined by neutron activation analysis (NAA), determining the gold concentration $([\mathrm{Au}])$ in the Chilean Nuclear Energy Commission (CCHEN) as already described. ${ }^{21}$ With the data of length and width, the averages of GNR and [Au] were determined by TEM, and the GNR concentration was determined by the following equation. ${ }^{37} \mathrm{zaa}[\mathrm{GNR}]=4 \times[\mathrm{Au}] / \mathrm{\rho Au} \times \pi \times \mathrm{W} \times$ $2 \mathrm{~L}$, where [GNR] is the GNR concentration, $\rho A u$ is the density of bulk gold atoms $\left(59\right.$ atoms $\left./ \mathrm{nm}^{3}\right),[\mathrm{Au}]$ is the gold concentration determined by gold neutron activation, $\mathrm{L}$ is the length of the GNR, and W is the width of the GNR.

To determine the quantity of peptide molecules that are bound to the GNR-peptide amino acids, an analysis was performed. Each GNR-peptide sample was hydrolyzed in $6 \mathrm{~N} \mathrm{HCl}$ with an internal standard (amino butyric acid) for $72 \mathrm{~h}$ and then lyophilized. Later, the solution was evaporated under reduced pressure and derivatized for amino acid analysis by HPLC.

\section{Small Angle X-Ray Scattering (SAXS)}

The liposomes were characterized using SAXS. All X-ray scattering measurements were carried out using an S3MICRO (Hecus X-ray systems GMBH Graz, Austria). $\mathrm{X}$-ray radiation with a wavelength corresponding to a $\mathrm{Cu}-$ $\mathrm{K} \alpha$ source $(1.542 \AA)$ was used. A Peltier TCCS-3 (Hecus $\mathrm{GmbH}$; Graz, Austria) temperature controller and the linear detector PSD 50 (Hecus; Graz, Austria) were used. The samples were injected in $1 \mathrm{~mm}$ diameter glass capillaries (Hilgenberg $\mathrm{GmbH}$; Malsfeld, Germany) as described in Rodríguez et al. ${ }^{38}$ The SAXS detector provides information about the larger structural units in the sample; namely, the lamellar repeat distance. The curves are shown as a function of the scattering vector modulus, $\mathrm{Q}=(4 \pi \sin \theta) / \lambda$, in which $\theta$ is the scattering angle and $\mathrm{Q}$ is the reciprocal $\AA$. The position of the scattering peaks is directly related to the repeat distance of the molecular structure, as described by Bragg's law. ${ }^{39}$ In a lamellar structure, the various peaks are located at equidistant positions, $\mathrm{Qn}=2 \pi \mathrm{n} / \mathrm{d}$, where $\mathrm{n}$ and $\mathrm{d}$ represent the order of the 
diffraction peak and repeat distance, respectively, and Qn represents the position of the nth order reflection.

\section{Dynamic Light Scattering (DLS)}

The hydrodynamic diameter (HD) and polydispersity index (PDI) of the lipid vesicles, GNR, GNR-peptide and mixes were determined by DLS using a Zetasizer Nano ZS (Malvern Instruments, UK). DLS measures the Brownian motion of the particles and correlates it to the particle size. The relationship between the size of a particle and its speed due to Brownian motion is defined in the Stokes-Einstein equation: $D=\kappa T / 6 \pi \eta r$, where $D$ is the translational diffusion coefficient, $\kappa$ is Boltzmann's constant, $\mathrm{T}$ is the absolute temperature, $\eta$ is the viscosity, and $r$ is the particle radius. The measurements were repeated five times for each sample. All experiments were performed at $25{ }^{\circ} \mathrm{C}$. Interpretation of the data was made by considering the size distribution of the intensity of light scattering. All data were obtained with the software provided by Malvern Instruments.

\section{Zeta Potential}

The zeta potential (Zetasizer nano ZS, Malvern Instruments, UK) measurements were repeated five times for each GNR sample. Since the zeta potential measurements were performed in an aqueous solution, the Smolochowski approximation was used to calculate the zeta potential from the electrophoretic mobility measured.

\section{Cryo-Transmission Electron Microscopy (cryo-TEM) \\ GNR-CArg ${ }_{7}$ LPFFD was visualized using cryo-TEM.}

A thin aqueous film was formed by dipping and withdrawing a bare specimen grid from the suspension. Glowdischarged holey carbon grids were used. After withdrawal from the suspension, the grid was blotted against filter paper, which left thin sample films that spanned the grid holes. These films were vitrified by plunging the grid into ethane, which was kept at its melting point by liquid nitrogen, using a Vitrobot ${ }^{40}$ (FEI Company, Eindhoven, Netherlands) and keeping the sample at $100 \%$ humidity before freezing. The temperature at which the thin films were kept and where vitrification was initiated, was $37^{\circ} \mathrm{C}$. The vitreous sample films were transferred to a Tecnai F20 microscope (FEI Co., Eindhoven, Netherlands) using a Gatan cryotransfer (Barcelona, Spain). Visualization was obtained at $200 \mathrm{kV}$ at a temperature between -170 and $-175{ }^{\circ} \mathrm{C}$ using low-dose imaging conditions.

\section{GNR and GNR-Peptide Interactions with the Liposome}

Interactions between the liposome and each GNR/GNR peptide were monitored over time using DLS and cryoTEM. For this, $0.25 \mathrm{mM}$ liposomes were mixed with 0.5 nM GNR or GNR-peptide in Milli-Q water. All mixtures were immediately used.

\section{Isotherm of the SI00 Phospholipid Mixture at the Air-Water Interface}

A Langmuir balance (Nima Technologies, Ltd., Coventry, England) with a surface tension precision of $0.1 \mathrm{mN} / \mathrm{m}$ and equipped with a Langmuir Blodgett trough (Model 611) was used to obtain S100 mixture isotherms. For this, S100 was dissolved in chloroform to a final concentration of $1 \mathrm{mg} / \mathrm{mL}$ and spread on the Langmuir trough surface. The surface pressure $(\pi=\gamma 0-\gamma$; ie, the surface tension difference between the clean water surface and the covered surface) was measured using the Wilhelmy plate method. Specifically, S100 $(8 \mu \mathrm{L})$ was spread with a Hamilton microsyringe on a clean water $(18.3 \mathrm{M} \Omega \cdot \mathrm{cm})$ surface or on different aqueous suspension constructs with GNRs (final concentration of $3.01 \times 10^{9} \mathrm{GNR} / \mathrm{mL}$ ). All experiments were performed in a dust-free glass box. After surface cleaning and chloroform solution spreading on the subphase $(50 \mathrm{~mL})$, isotherm analyses were performed 15 min after the S100 samples were spread to allow for chloroform evaporation. When aqueous GNR suspensions were used as the subphase, isotherm analyses were performed after $1 \mathrm{~h}$. The isotherm analyses were repeated three times, with an average relative error of $2 \%$ when using a compression rate of approximately $20 \mathrm{~cm}^{2} / \mathrm{min}$. All experiments were performed at $25^{\circ} \mathrm{C}$.

\section{Cell Viability Assay}

The SH-SY5Y cell line (from ATCC) was maintained in DMEM high-glucose medium (GIBCO) containing 10\% inactivated fetal bovine serum (FBS), $100 \mathrm{U} / \mathrm{mL}$ penicillin, and $100 \mu \mathrm{g} / \mathrm{mL}$ streptomycin in a humidified atmosphere of $5 \% \mathrm{CO}_{2}$ at $37{ }^{\circ} \mathrm{C}$. To determine the effect of GNRs on cell viability, a 3-(4,5-dimethylthiazol-2-yl)-5-(3-carboxymethoxyphenyl)-2-(4-sulfophenyl)-2H-tetrazolium (MTS) assay was performed to establish a linear relationship between the viable cell percent and the absorbance. For the MTS assay, SH-SY5Y cells were seeded in 96-well plates at 3000 cells per well. The cells were then treated with increasing concentrations of GNRs or GNR-peptide. After $24 \mathrm{~h}$ of 
incubation, the cell viability was measured (in triplicate) in three independent experiments using the MTS assay according to the manufacturer's protocol (CellTiter $96{ }^{\circledR}$ AQueous Assay, Promega). The absorbance at $490 \mathrm{~nm}$ was measured on a multiscan reader with a reference wavelength of $655 \mathrm{~nm}$.

The use of SH-SY5Y cell line (from ATCC) in Chile does not require the ethical approbation.

\section{GNR and GNR-Peptide Cell Penetration}

Neuroblastoma cells (SH-SY5Y) were incubated with GNR-peptide for $24 \mathrm{~h}$. Cells were fixed with 3\% glutaraldehyde in Sörensen phosphate buffer $(0.1 \mathrm{M}, \mathrm{pH} 7.3)$ and then kept in fixative medium at $4{ }^{\circ} \mathrm{C}$ for $4 \mathrm{~h}$. The cells were then washed with Sörensen phosphate buffer and postfixed with $2 \%$ osmium tetroxide at $4{ }^{\circ} \mathrm{C}$. The samples were then dehydrated in acetone, infiltrated with EPON resin for 2 days, embedded in the resin, and polymerized at $70{ }^{\circ} \mathrm{C}$ for 48 h. Ultrathin sections were obtained using a Sorvall Porter-Blum ultramicrotome and mounted on formvarcoated copper grids. The sections were stained with $2 \%$ uranyl acetate in water and lead citrate and then observed under a JEM-1010 electron microscope (JEOL, Japan).

\section{Data Analysis}

All results are presented as the mean \pm SEM from at least three independent experiments. Statistical analysis of the data was performed using GraphPad Prism 5 Software. Kruskal-Wallis statistics followed by Dunn's post hoc tests were used and considered significant at $\mathrm{p} \leq 0.05$.

\section{Results and Discussion Characterization of GNR-Arg 7 CLPFFD, GNR-CArg 7 and the Liposomes}

To obtain GNR-Arg ${ }_{7}$ CLPFFD, GNRs were incubated with the peptide $\operatorname{Arg}_{7}$ CLPFFD. The peptide $\operatorname{Arg}_{7}$ CLPFFD could be chemisorbed through the thiol contained on the cysteine to the GNR surface as described previously for the functionalization of GNR with the peptide CLPFFD. ${ }^{21,41}$ For modification of the GNR surface, peptides that have a cysteine residue $(\mathrm{C})$, which contains a thiol group (-SH), allows for a strong interaction with the gold surface by means of chemisorption $(\mathrm{S}-\mathrm{Au}){ }^{42}$ The chemisorption of thiols on the gold surface is a favored process frequently used to functionalize gold nanoparticles. ${ }^{41}$ In this way, the CTAB contained on the surface of the GNR is replaced by the thiol. ${ }^{21}$ The peptide-conjugated GNRs were characterized using TEM, Vis-NIR spectrophotometry, DLS, and amino acid analyses. The size and aspect ratios of the peptideconjugated GNR were obtained by TEM (Figure 1A-C). The average lengths of GNR-Arg ${ }_{7}$ CLPFFD and GNR$\mathrm{CArg}_{7}$, each calculated from 100 nanorods, were $49 \pm 1.8$ and $43 \pm 0.7 \mathrm{~nm}$, respectively. Additionally, the average widths were $12 \pm 0.2$ and $12 \pm 0.3 \mathrm{~nm}$, respectively. The median aspect ratio of all conjugates was 4.1, while the specific average ratios were $4.4 \pm 0.9$ (GNR-Arg 7 CLPFFD) and $3.9 \pm 0.8$ (GNR-CArg ${ }_{7}$ ) (Figure 1A and B). The spectra obtained were in the near infrared zone, with a longitudinal surface plasmon resonance centered at 790 $\mathrm{nm}$, compared to the unconjugated GNR, which was centered at $780 \mathrm{~nm}$ (Table 1). This bathochromic shift to a longer wavelength was consistent with the chemisorption of the peptides on the GNR surface (Figure 1C), as described for other peptides conjugated to gold nanoparticles. ${ }^{21}$

The GNR-peptide size distribution DLS measurements exhibited two size distribution peaks, one with a hydrodynamic diameter (Hd) of 3-5 $\mathrm{nm}$ and one of approximately $50 \mathrm{~nm}$ with a polydispersity index (PDI) of 0.4 (Table 1). The small size peak was attributed to the rotational diffusion of the nanorods instead of the actual dimension of the nanorods. ${ }^{43}$

The zeta potentials of GNR-Arg 7 CLPFFD and GNR$\mathrm{CArg}_{7}$ were $37 \pm 0.7$ and $32 \pm 3.5$, respectively (Table 1), without significant differences between them; the positive values were possibly due to the positive charges of the peptides at $\mathrm{pH}$ 5. In comparison to GNR-CLPFFD (51 \pm $1.3)$ and unconjugated GNR $(56 \pm 2.9)$, the GNRs functionalized with $\operatorname{Arg}_{7} \mathrm{CLPFFD}$ or $\mathrm{CArg}_{7}$ displayed slight reductions in surface charge, as determined by zeta potential measurements (Table 1). These effects were most likely caused by a displacement of the CTAB molecules that formed the bilayer during functionalization. ${ }^{44}$

To evaluate the stability of the peptide-conjugated GNR in the solutions used in the present study, GNR-CLPFFD and GNR-Arg 7 CLPFFD were incubated at $\mathrm{pH} 7$ in an aqueous solution and in cell culture medium (high glucose DMEM, 10\% FBS) at 27 and $37^{\circ} \mathrm{C}$. Samples were periodically collected over $24 \mathrm{~h}$ to obtain the Vis-NIR spectra (Figure S1). With the exception of GNR-CLPFFD at $24 \mathrm{~h}$, the plasmon bands of the peptide-conjugated GNRs did not appreciably change, suggesting that the colloids were stable at the two tested temperatures.

The peptide loading of each GNR was calculated by dividing the amount of peptide (obtained by amino acid analysis of the GNR pellet) by the amount of GNRs in solution, which was determined by neutron activation 
A

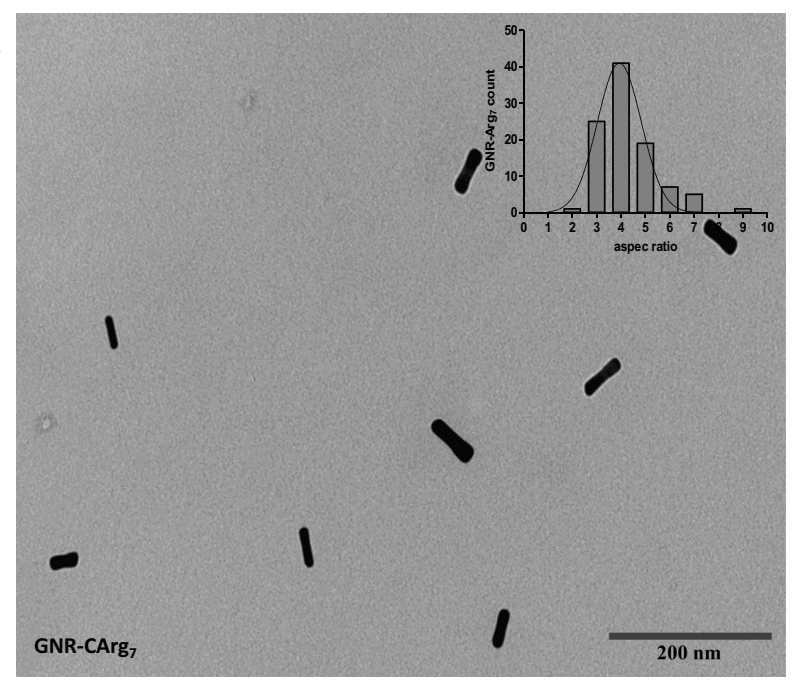

B

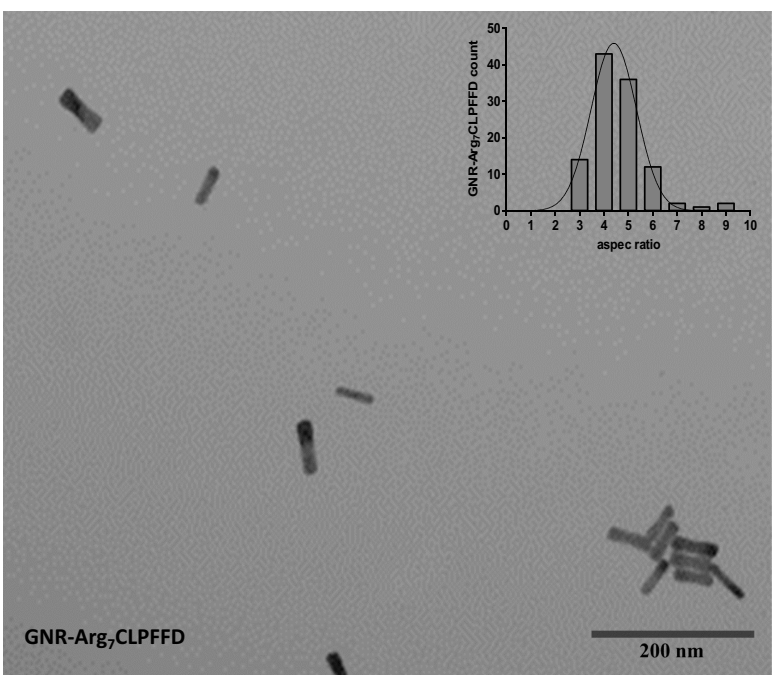

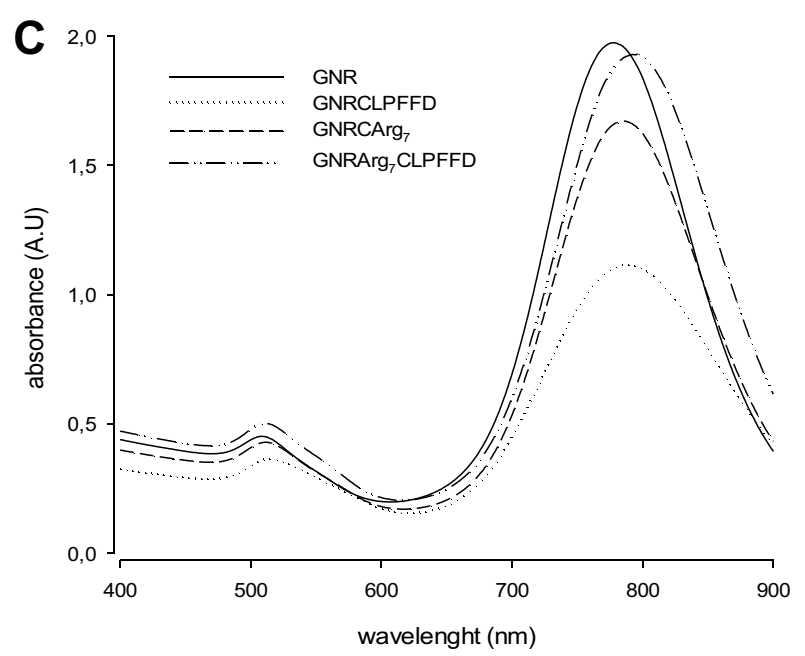

Figure I Characterization of the GNR-peptide. Representative TEM images and insert (histogram of aspect ratio length/width of I00 nanoparticles) of (A) GNR-CArg 7 and (B) GNR-Arg 7 CLPFFD; (C) Absorption spectrum of GNR and GNR-peptide.

analysis and considered the TEM obtained diameters (see the experimental section). There were 909 peptide molecules in GNR-Arg ${ }_{7}$ CLPFFD. Previous studies reported the conjugation of GNR-CLPFFD with 1812 peptides, ${ }^{21}$ a load twice that of $\operatorname{Arg}_{7}$ CLPFFD. The decreased peptide

Table I Characterization of the GNRs and the GNR-Peptides, Including the Longitudinal Surface Plasmon Resonance, Zeta Potential $(\mathrm{mV})$ and Dynamic Light Scattering (d.nm)

\begin{tabular}{|c|c|c|c|}
\hline GNR-Peptide & $\lambda(\mathrm{nm})$ & $(H d)^{a}$ (d.mn) & $\mathbf{Z P}(\mathbf{m v})^{a}$ \\
\hline GNR & 790 & $56 \pm 6.9$ & $56 \pm 2.9$ \\
\hline GNR-CLPFFD & 796 & $56 \pm 7.1$ & $51 \pm 1.3$ \\
\hline GNR-CArg 7 & 789 & $43 \pm 9.0$ & $32 \pm 3.5^{*} \#$ \\
\hline GNR-Arg ${ }_{7}$ CLPFFD & 802 & $55 \pm 7.6$ & $37 \pm 0.7^{*, \#}$ \\
\hline
\end{tabular}

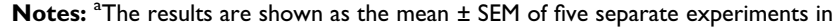
triplicate, ${ }^{*} \mathrm{p}<0.05$ with respect to GNR; ${ }^{*} \mathrm{p}<0.05$ with respect to GNR-CLPFFD. load could be explained by the steric hindrance of $\operatorname{Arg}_{7}$ CLPFFD. These peptides were positioned in the "Y" form on the GNR surface. The bottom portion of this form corresponded to the Cys residue, which allows for peptide chemisorption onto the GNR surface. In turn, the oligoarginine and LPFFD chains are exposed to the solvent. Conversely, CLPFFD was positioned orthogonally to the GNR surface, thus allowing for the accommodation of more peptide molecules.

Liposome size, morphology, and structural topology were characterized by small angle X-ray scattering, DLS, and cryo-TEM. The size distribution curves of liposomes at room temperature were visualized (Figure S2A), and only one peak was observed. This peak centered on a population with a diameter of $146 \pm 0.9 \mathrm{~nm}$ and a PDI of 0.2 (Figure S2A). Cryo-TEM analysis of the 
morphology revealed predominantly unilamellar liposomes with sizes ranging from 100 to $150 \mathrm{~nm}$ (Figure $\underline{\mathrm{S} 2 \mathrm{~B}})$. Therefore, the data obtained by cryo-TEM and DLS were consistent. Additionally, small-angle X-ray diffraction patterns for the liposomes showed two reflections, a result most likely associated with the first and secondorder Bragg distances $(\mathrm{d}=6.1 \mathrm{~nm})$ of ordered unilamellar structures (Figure S2C).

\section{Membrane Model Interactions with GNRs}

To evaluate whether oligoarginine CPPs increase the ability of GNRs to cross biological membranes, the interactions were observed between the conjugates and liposomes, a biological membrane model.

First, we used dynamic light scattering (DLS) to identify the different representative peaks of liposomes and peptide-
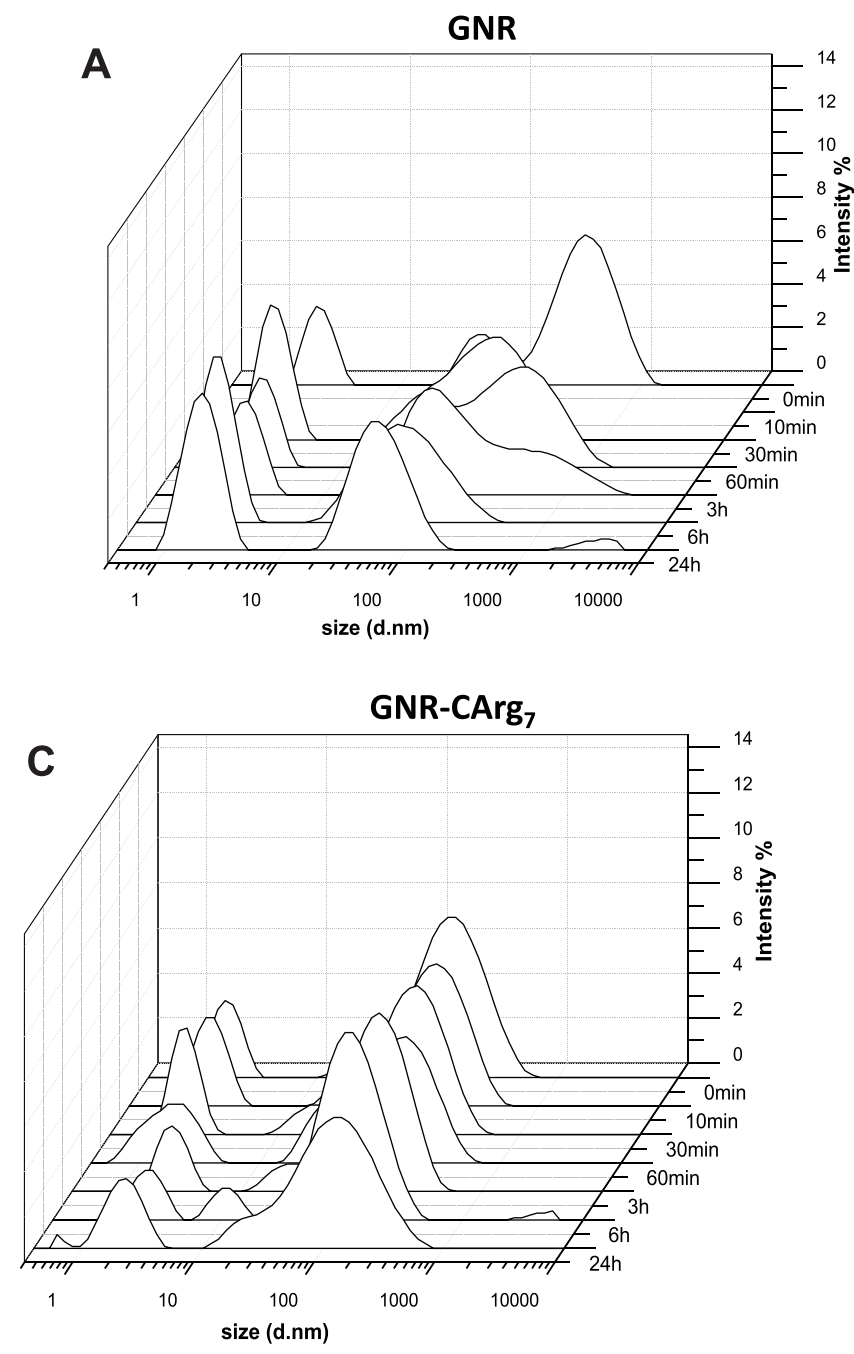

conjugated GNR and monitor the nanoparticle intensity distribution (percent) or size change. For this study, under kinetic conditions, the liposomes $(0.25 \mathrm{mM})$ were mixed with peptide-conjugated GNRs or unconjugated GNRs ( 0.5 $\mathrm{nM}$ ), and intensity curves vs Hd were measured at different incubation times over $24 \mathrm{~h}$. Three peaks were observed (Figure 2). These peaks were centered at approximately 3-5 $\mathrm{nm}$ and $50 \mathrm{~nm}$, which were associated with GNRs size, ${ }^{43}$ and $150 \mathrm{~nm}$, associated with liposome size. Neither the control GNRs nor the GNR-CLPFFD conjugate presented considerable changes over time (Figure 2A and B). However, when GNRs were conjugated with oligoarginine (GNR-CArg 7 and GNR-Arg 7 CLPFFD), the peaks (3-5 nm) for GNR-CArg $_{7}$ were reduced after $3 \mathrm{~h}$ of incubation (Figure 2C), and the representative peaks for GNR-Arg 7 CLPFFD (3-5 and $50 \mathrm{~nm}$ ) decreased over time (Figure 2D).
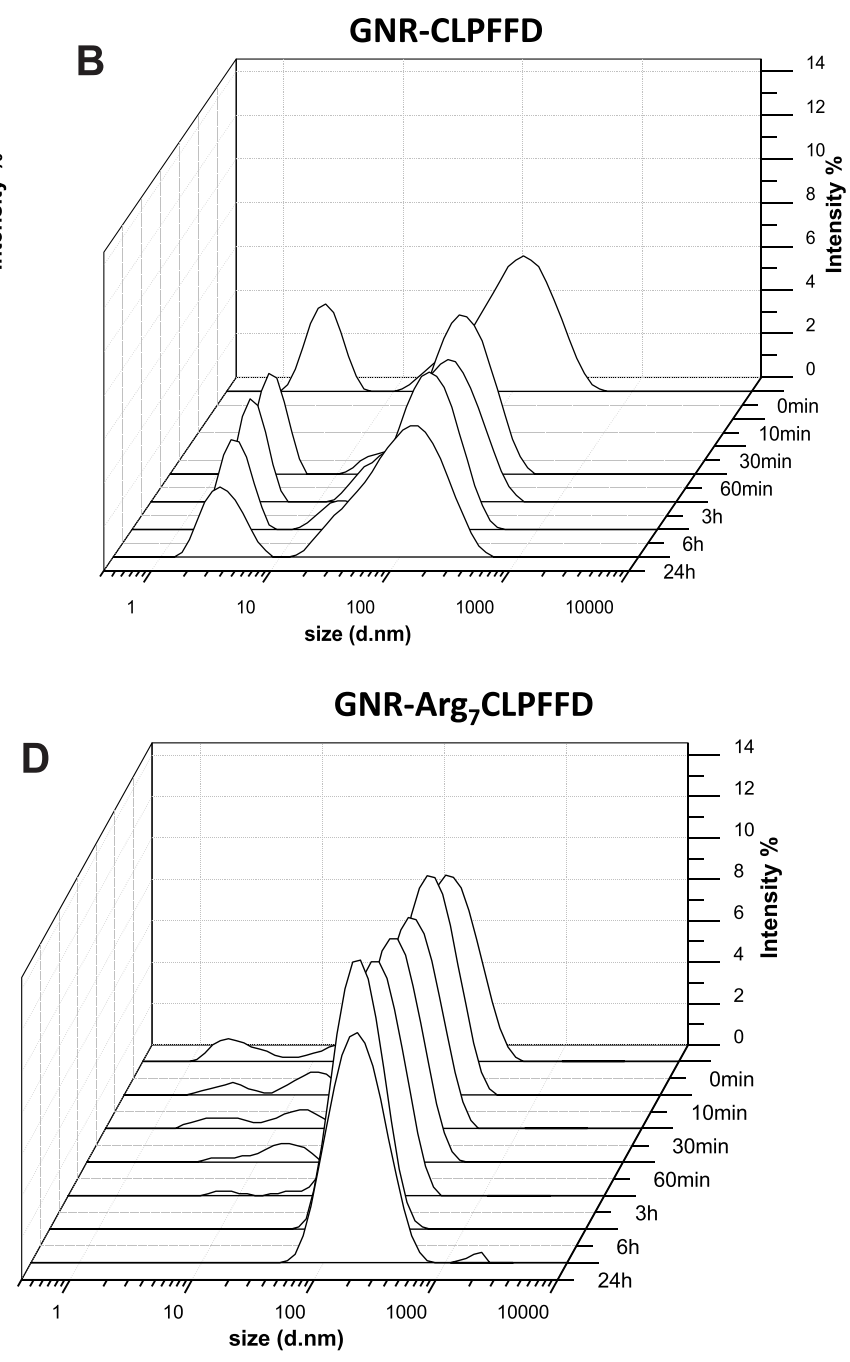

Figure 2 Interaction of liposomes with nanoparticles by average dynamic light scattering over time. Representative spectrum of \% intensity vs d.nm over time (0-24 h) of (A) GNR; (B) GNR-CLPFFD; (C) GNR-CArg 7 and (D) GNR-Arg 7 CLPFFD 
With the purpose of simplifying this analysis, highresolution spectra were obtained and expressed as a percent of the fitted peak areas (Table S1) for both GNRs peaks $(3.5 \mathrm{~nm}$ and $50 \mathrm{~nm})$. Figure 3 shows the fitted peak areas (\%) of the GNR centered at approximately $3.5 \mathrm{~nm}$.

For the first peaks (3-5 nm), GNR-Arg ${ }_{7}$ CLPFFD decreased $80 \%$ at time $3 \mathrm{~h}$ (Figure $3 \mathrm{~A}$, Table S1) with respect to time zero, and after $24 \mathrm{~h}$ of incubation, the fitted peak areas (\%) were close to zero (Figure 3A). Moreover for the peak at $50 \mathrm{~nm}$ the intensity decreased by $50 \%$ at 3h. However, for GNR-CArg 7 clear diminution of intensity was observed only for the peak at $50 \mathrm{~nm}$ at time $3 \mathrm{~h}$ (Figure 3B).

This can be interpreted as the integration of the GNR$\operatorname{Arg}_{7}$ CLPFFD with the liposomes, either covering the lipid bilayer or entering the inner portion of the liposome. These results allow us to postulate that the conjugation of GNR with oligoarginine peptides leads to enhanced interactions with lipid membranes. Nevertheless, it is important to note that GNR-CArg 7 have not a significant decrease over time (Figure 3). This implies that the LPFFD peptide plays an important role in this interaction. An electrostatic interaction is the main nonspecific interaction mechanism described for CPPs and the cell membrane. This type of interaction depends on structural characteristics such as charge density, epitope length, and chain flexibility. Interactions with the membrane can cause disruption of the lipid bilayer organization, either by fusion, fission, or pore formation, which is an important requirement for internalization. ${ }^{29,45,46}$

A

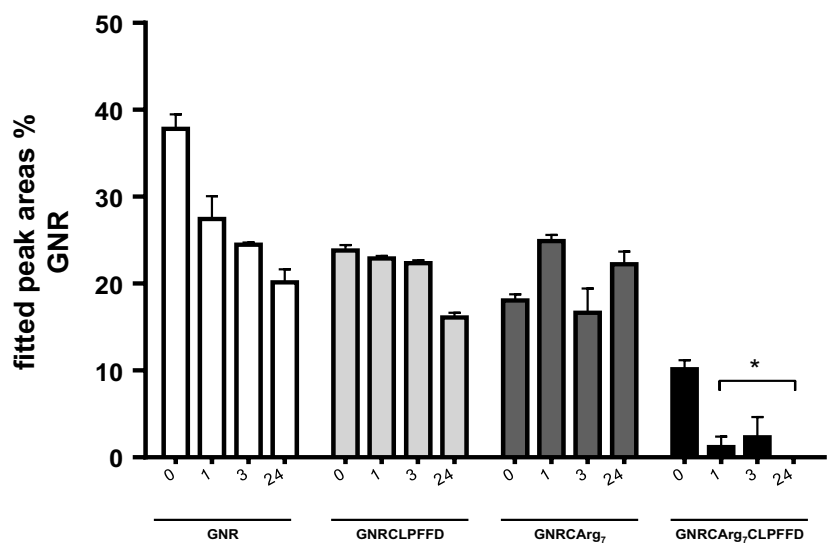

Further assessments were performed for the interactions of GNR, GNR-CArg 7 , and GNR-Arg ${ }_{7}$ CLPFFD with an S100 monolayer at the air-water interface. Specifically, the GNR$\mathrm{CArg}_{7}$ and GNR-Arg ${ }_{7}$ CLPFFD interactions were evaluated after modification of the $\mathrm{S} 100$ isotherm. Figure 4 shows the Langmuir isotherms and the compressional modulus behavior (Figure 4 inset) of S100 at the air-water interface in the presence of GNR, GNR-CArg 7 , and GNR-Arg ${ }_{7}$ CLPFFD in the aqueous subphase. The compressional modulus was defined using Equation 1:

$$
\mathrm{Cs}^{-1}=-\mathrm{Ad} \pi / \mathrm{dA}
$$

where $\mathrm{Cs}^{-1}$ is the compressional modulus, $\pi$ is the surface pressure, and $\mathrm{A}$ is the surface area. $\mathrm{Cs}^{-1}$ has been used to characterize the mechanical properties of lipid and phospholipid monolayers. ${ }^{36,47,48}$ It is already known that the compressional modulus is a very helpful and precise parameter to recognize the presence of specific phases and transition from one phase to another for monolayers at the air-water interface. Barraza et $\mathrm{al}^{48}$ analyzed the presence of mixtures with chitosan in stearic acid and cholesterol monolayers and found a decrease in the compressional modulus. It is interesting to mention that at the beginning of the LE-LC transition, a local maximum of the compressional modulus was found. Similar behavior was found with DPPC/bactenecin ${ }^{49}$ and DPPC/albumin mixtures at the airwater interface. ${ }^{50}$ In the present study, the representative S100 isotherm, which was extracted from soybean oil and consists of a mixture of three different phospholipids ${ }^{51}$ is presented in Figure 4 (solid black line). At large surface areas, S100 molecules behave as a two-dimensional gas $\left(>121 \AA^{2}\right)$. As compressional barriers reduce the surface

B

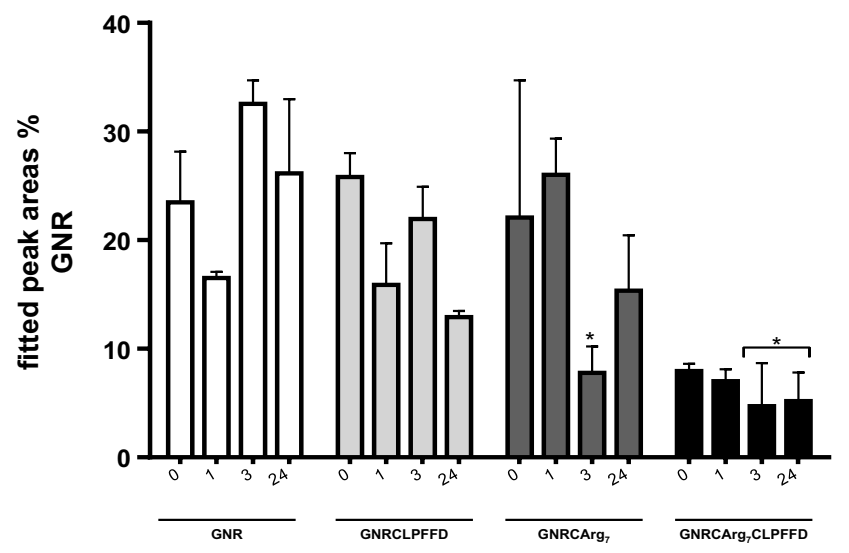

Figure 3 Percentage fitted peak area GNR and GNR-peptide with liposome over time (0-24 h). (A) 3-5 nm peak and (B) $50 \mathrm{~nm}$ peak. Values represent mean \pm SEM of three separate experiments $(* \mathrm{p}<0.05)$. 


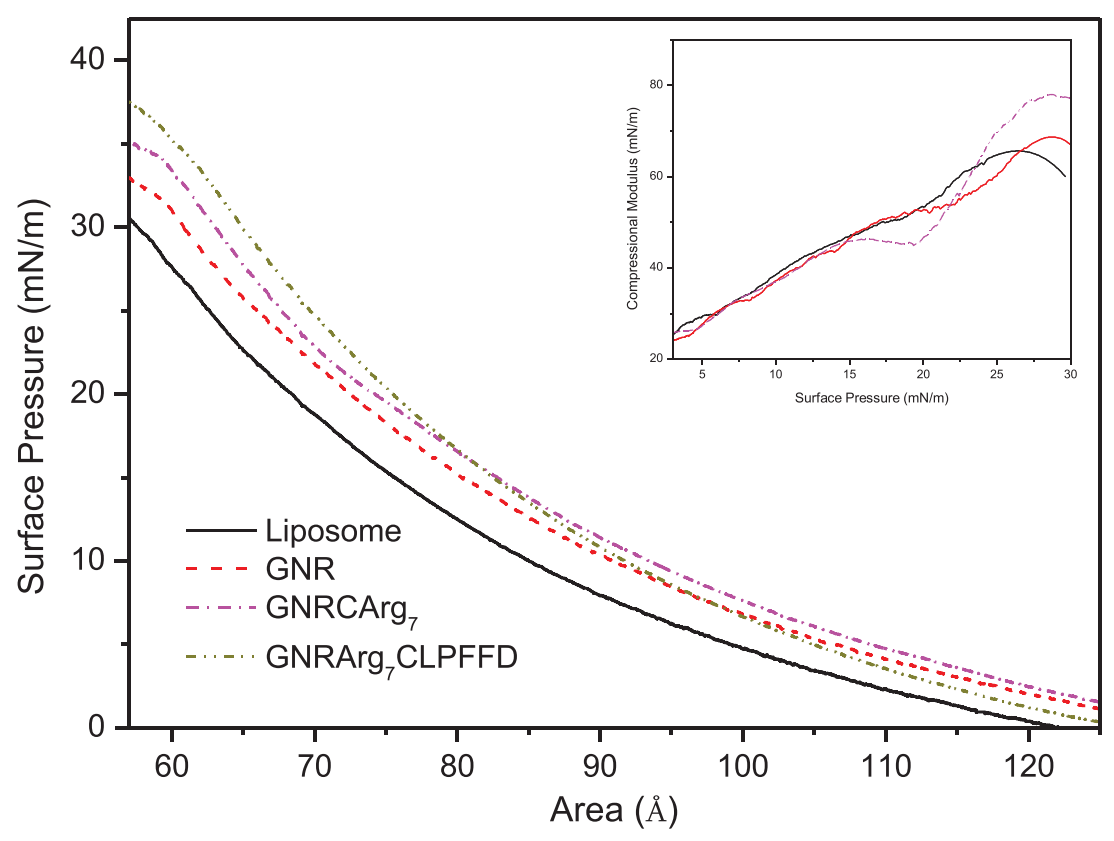

Figure 4 Langmuir isotherms and the compressional modulus (inset figure). Isotherms of the S- 100 phospholipid mixture at the air-water interface with GNR, GNR-CArg 7 and GNR-Arg ${ }_{7}$ CLPFFD in the aqueous subphase. Isotherms represent the mean with relative error of $2 \%$, $n=3$. All experiments were performed at $25{ }^{\circ} \mathrm{C}$.

area $\left(<121 \AA^{2}\right)$, the intermolecular interaction between S100 molecules becomes important, increasing the $\pi$ values, and a liquid expanded (LE) phase is formed.

With continued compression of the S100 phospholipids, the $\pi$-A isotherm does not show a horizontal plateau region because of the multiple components present in the phospholipid sample, showing a first-order phase transition from LE to the liquid condensing (LC) phase. The $\pi$-A isotherms of S100 recorded when GNR, GNR-CArg ${ }_{7}$, or GNR-Arg 7 CLPFFD were added into the water subphase show similar behavior, but they shifted to higher surface areas and showed an increment of $\pi$ values. For example, the short gaseous phase shown by S100 phospholipids disappeared when GNRs or peptide-conjugated GNRs were introduced into the subphase. This suggests that GNRs are preadsorbed on the interface and interact with the S100 components before surface area compression, and GNRs remain attached to the S100 monolayer during the whole compression process. At the end of the LC phase, the phospholipidic components of S100 are relatively vertically oriented and closely packed; thus, extrapolating this line region of the isotherm to zero pressure, the molecular area $\left(\mathrm{A}_{0}\right)$ can be attained, where the corresponding value of $\mathrm{A}_{0}$ is the intercepting point of the line that crosses the $\mathrm{x}$-axis. Then, the $\mathrm{A}_{0}$ values of S100 increased when GNR, GNR-CArg ${ }_{7}$, and GNR-Arg ${ }_{7}$ CLPFFD were added to the water subphase from 86 to 90,92 , and $94 \AA^{2}$, respectively. The surface between
S100 molecules and GNRs can be described by the $\mathrm{Cs}^{-1}$ (Figure 4 inset) parameter, since it gives information about the lateral interaction that occurs at the air-water interface. For instance, the progressive increment of $\mathrm{Cs}^{-1}$, observed from 125 to $82 \AA^{2}$, indicates strong interactions between phospholipid components of S100 with GNR, GNR-CArg ${ }_{7}$, and GNR-Arg ${ }_{7}$ CLPFFD. Moreover, the high values of $\mathrm{Cs}^{-1}$ at the end of the compression process (high pressure) suggest that peptide-conjugated GNRs were attached to the S100 phospholipids and are not expelled from the monolayer. These results are in agreement with the previous S100 liposome and oligoarginine conjugated GNR (GNR-CArg 7 and GNR-Arg ${ }_{7}$ CLPFFD) interaction study by DLS, supporting that both GNR-CArg ${ }_{7}$ and GNR-Arg ${ }_{7}$ CLPFFD integrate and stabilize the membrane of the S100 liposomes.

Finally, we mention that the behavior of the compressional modulus of the S100 mixed with GNR and the mixtures with the peptides GNR-CArg ${ }_{7}$ and GNR-Arg ${ }_{7}$ CLPFFD at higher pressure is contrary to that expected for DPPC and different mixtures. ${ }^{48-50}$ There, the compressional modulus values decreased in comparison with the values for pure DPPC, producing more compressible monolayers. In contrast, as observed in Figure 4, the values of the modulus are higher than those observed for the pure S100 monolayer. This could be due to the large number of GNRs attached to the peptides and/or S100 molecules and to the increase in electrostatic repulsion, resulting in a more rigid monolayer. 
In addition, as can be observed in the isotherm for $\mathrm{S} 100$, the proportion of DPPC in the monolayer is lower than that used in, ${ }^{48-50}$ resulting in different behavior.

To further complement these biophysical studies, cryoTEM analysis was performed. Figure 5 shows representa-

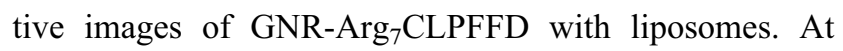
time 0 , the nanoparticles tended to interact with the lipid membrane, and over time, this interaction increased (Figure 5, figure S3). After $24 \mathrm{~h}$, the GNR peptides were arranged in an orderly manner around the liposomes (Figure 5, Figure S3). These analyses facilitated observations on how GNRs interact with the S100 lipid membrane. We can suggest that GNR-Arg ${ }_{7}$ CLPFFD interacts from time zero with liposomes and that most likely the nanoparticles are organized around the liposome.

Altogether, the applied techniques demonstrated that GNR conjugation with amphipathic peptides, such as CLPFFD, and with oligoarginine CPPs enhanced interactions between GNR and a biological membrane model. First, the positively charged $\mathrm{Arg}_{7}$ peptide would allow interactions with the negatively charged molecules of biological membranes. Then, the CLPFFD amphipathic portion would allow the integration and stabilization of the GNR into the membrane.

\section{Cell Internalization and Viability of GNR, GNR-CLPFFD, GNR-Arg ${ }_{7}$ CLPFFD, and GNR-CArg 7}

To evaluate the improved biophysical properties of peptideconjugated GNR, their intracellular localization was studied in the human neuroblastoma cell line SH-SY5Y using TEM. This cell line was chosen for the purpose of directing GNRs into the brain, which could have future therapeutic applications. First, the effects of the peptide-conjugated GNRs on cell viability were evaluated using a colorimetric method. This method was based on MTS reduction to formazan by mitochondrial enzymes of viable cells; the percent of MTS reduction is an indicator of cell viability. SH-SY5Y cells were incubated with different concentrations $(0.08$, 0.24 , and $0.4 \mathrm{nM}$ ) of peptide-conjugated GNRs or GNRs for $24 \mathrm{~h}$. Naked GNRs reduce the cell viability, which could be attributed to the presence of CTAB (Figure S4), as was reported previously by our group. ${ }^{21}$ The CTAB layer present in the naked GNR can be replaced by CLPFFD or by $\operatorname{Arg}_{7}$ CLPFFD due to the chemisorption of the thiol on the gold surface reducing the effects on cell viability.

At the studied concentrations, GNR-CLPFFD and GNR-Arg ${ }_{7}$ CLPFFD did not affect cellular viability (Figure 6A and B), with the exception of GNR-CArg $_{7}$, which reduced the cell viability by $20 \%$ (Figure $6 \mathrm{C}$ ), which can be considered slight cytotoxicity. ${ }^{52}$

These results are consistent with those reported by Morales-Zavala et al, who tested the effects of nanodiamonds functionalized with R7-CLPFFD on cell viability in two different cell lines (HT22 hippocampal neurons and 3 T3 fibroblast cells) without cytotoxic effects. ${ }^{53}$ Moreover, Maiolo et al 2005 demonstrated that the oligoarginine CPPs R7 and R7W are highly toxic to eukaryotic cells, in contrast to CPPs rich in arginine and negatively charged amino acids, such as R7-DTRL and R7W-VQD. ${ }^{54}$ In this respect, several studies have assessed the effects of cationic CPPs on cell viability, describing that CPP toxicity is highly dependent on the sequence, concentration, nature of the cargo molecule and coupling strategy. ${ }^{54-57}$

On the other hand, as was also demonstrated by Amani et al, the functionalization of GNPs with proteins such as
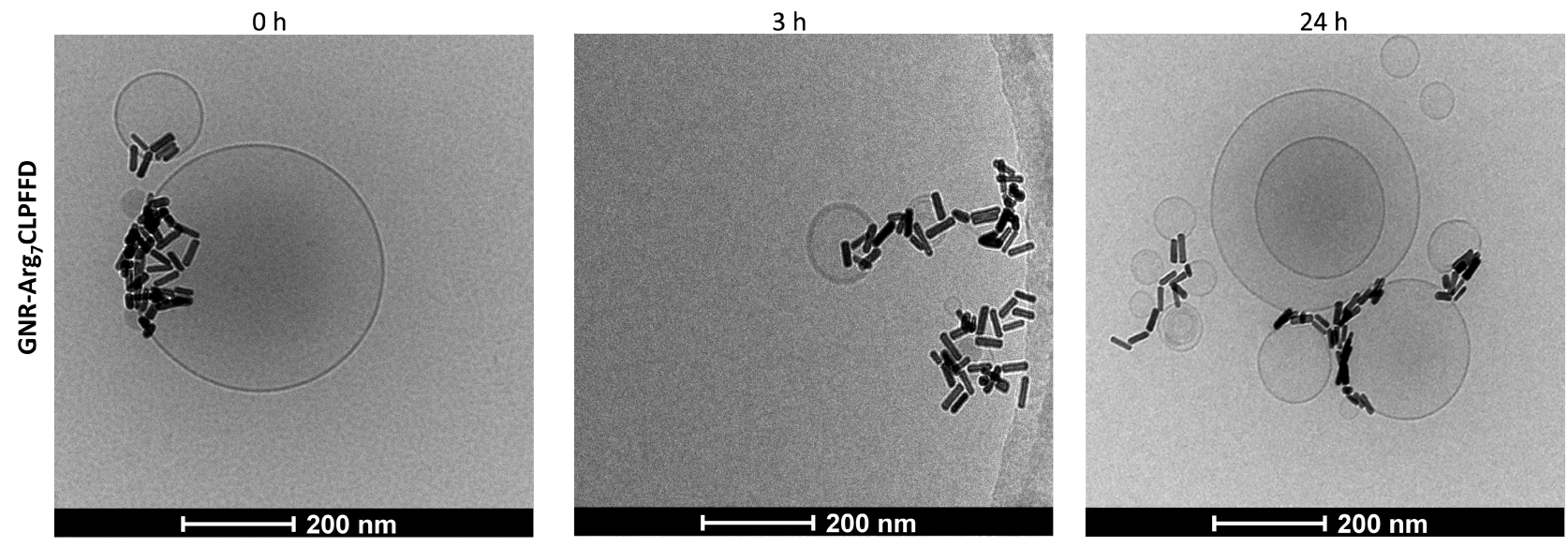

Figure 5 Representative cryo-transmission electronic microscopy image of the interaction of GNR-Arg 7 CLPFFD with liposomes at different times (0, 3 and 24 h). 

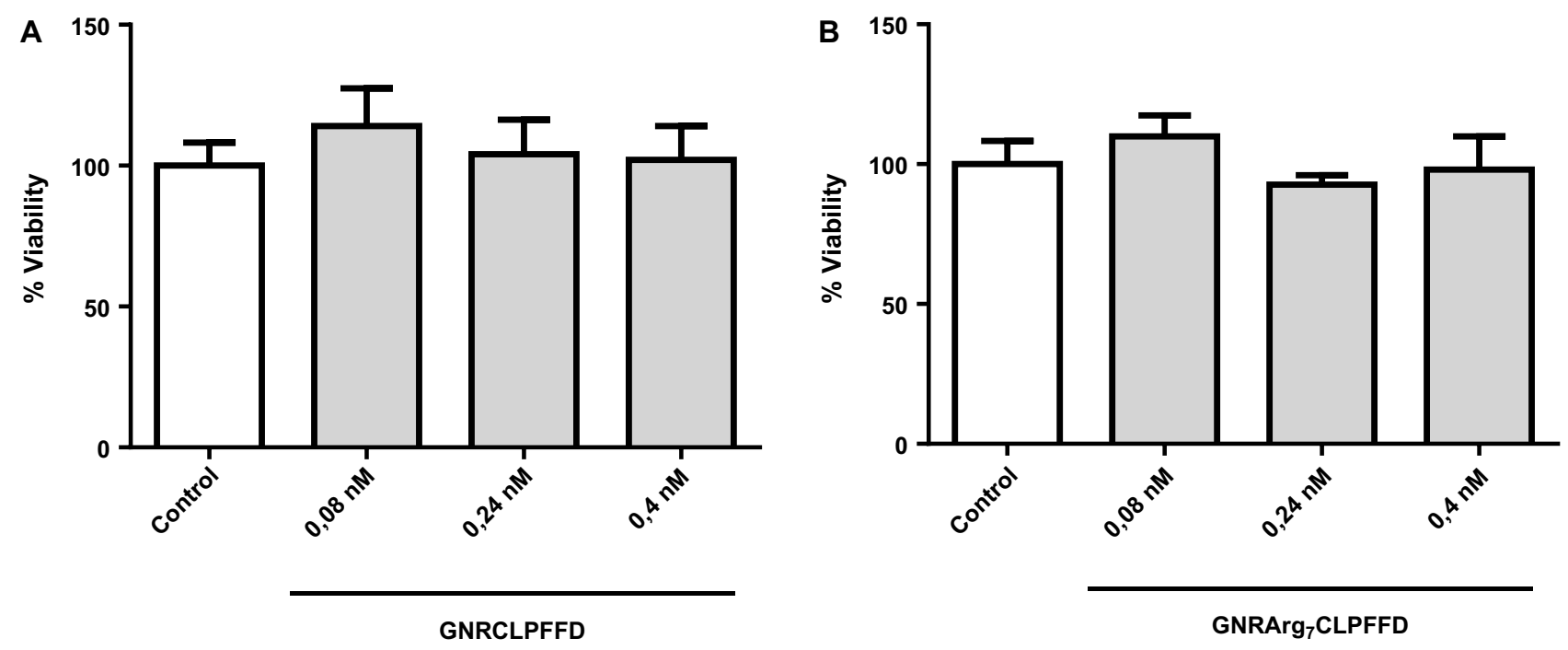

GNRArg ${ }_{7}$ CLPFFD

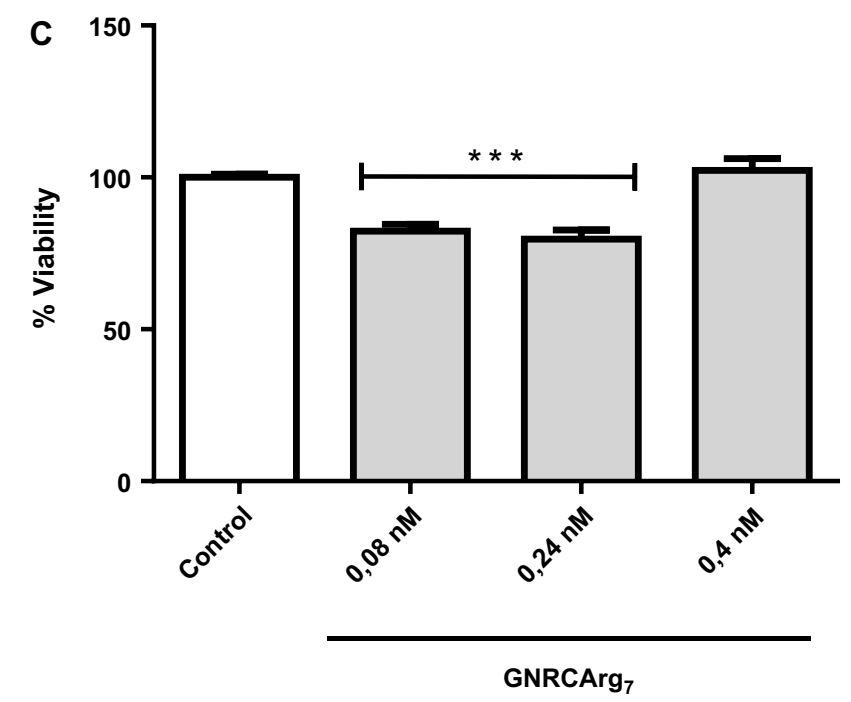

Figure 6 Cellular viability in SH-SY5Y cells treated with (A) GNR-CLPFFD; (B) GNR-Arg 7 CLPFFD; and (C) GNR-CArg7 at different concentrations (0.08-0.4 nM) for $24 \mathrm{~h}$. The control was without nanoparticles. The data are expressed as the percent of living cells. Values represent the mean \pm SEM of three separate experiments in triplicate $(* * * 0.001)$.

the antibody OX26 can increase the surface charge, increasing the cytotoxicity. In this respect, the specific biomedical applications for which the peptide-conjugated GNR is being designed are very important, and specific studies are necessary to evaluate each case. ${ }^{58}$

To study penetrability, the different conjugates were incubated at a concentration of $0.4 \mathrm{nM}$ for $24 \mathrm{~h}$, and the processed samples were analyzed by TEM. Figure 7 shows representative TEM microphotographs of cells with, GNR-CLPFFD, $\mathrm{GNR}^{-C A r g}{ }_{7}$, or GNR-Arg $_{7}$ CLPFFD. Figure 7D summarizes the quantity of GNRs per cell, which were counted for each condition (25-55 cells per condition). Cells treated with GNR-Arg ${ }_{7}$ CLPFFD internalized 65\% more nanoparticles $(31 \pm 7)$ (Figure 7C and D) than cells treated with
GNR-CLPFFD $(11 \pm 3)$ (Figure 7A and D) and 45\% more nanoparticles than cells treated with $\mathrm{GNR}_{-\mathrm{CArg}}(17 \pm 2)$ (Figure 7B and D). Additionally, internalization of the conjugates did not induce cell damage. Indeed, all organelles were easily distinguished and were in good condition, as was also observed for control cells (Figure S5). Notably, the conjugates were surrounded by a well-defined membrane structure that resembled a multivesicular body (Figure 7).

Independent of the cell penetration mechanism of our nanosystems, the first contact of the oligoarginines with the cell membrane is through hydrogen bonds with proteoglycans, such as heparin sulfate, ${ }^{46}$ and then the CPPs induced a structural curvature of the cell membrane for oligoarginine uptake. $^{46,59}$ 

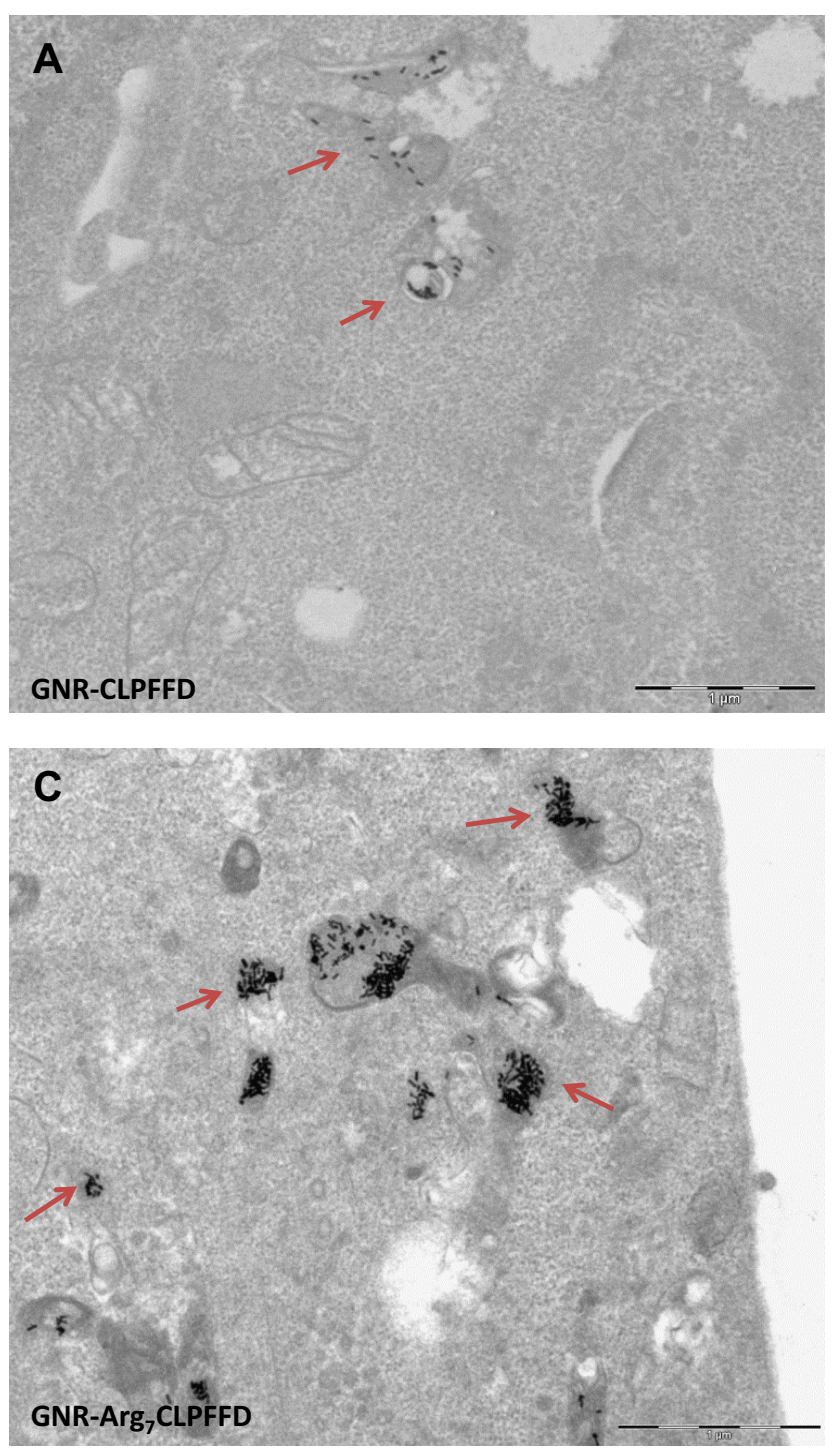

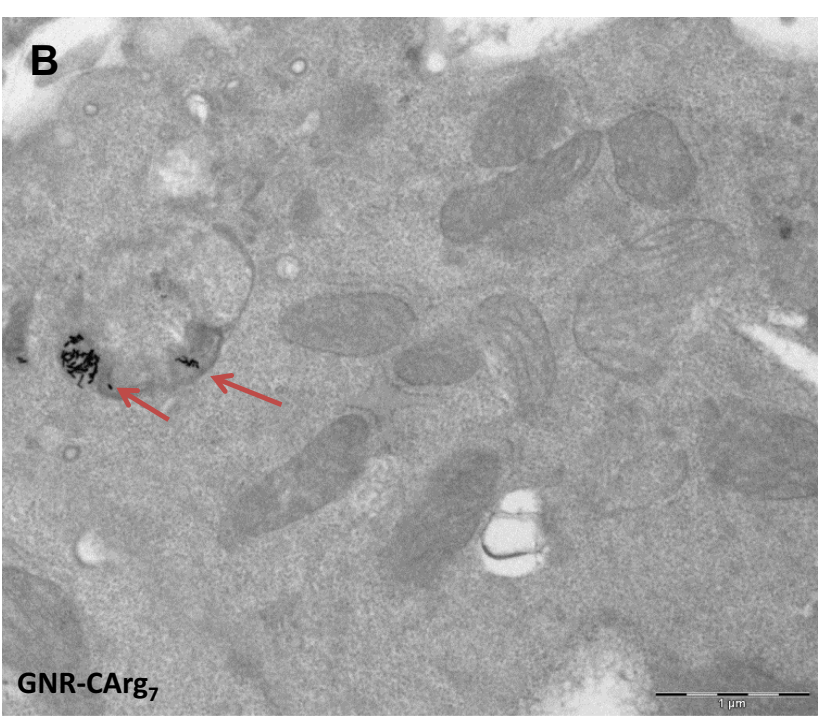

D

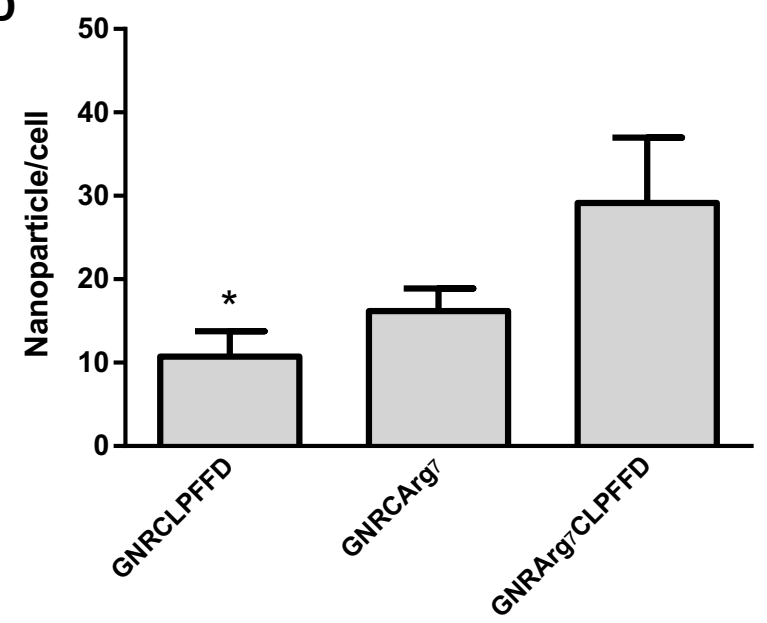

Figure 7 Representative TEM images of SH-SY5Y cells incubated with (A) GNR-CLPFFD; (B) GNR-CArg; (C) GNR-Arg7 CLPFFD for 24 h and (D) GNR-peptide per SHSY5Y cell, the results represent the mean \pm SEM, ${ }^{*} P<0.05$ with respect to GNR. Red arrows indicate the presence of nanorods inside the vesicles.

Although the focus of our paper is not to study the penetration mechanism of the GNR to the cells, it is important to discuss the possible cellular uptake mechanisms of CPPs. Nevertheless, there is a consensus that the endocytic pathway ${ }^{46}$ has a major role in the internalization of these peptides; however, in some cases, direct translocation across plasma membranes and cytosolic distribution of arginine-rich CPPs are still observed in cells without membrane perturbation. ${ }^{60}$

The endocytic pathways that contribute to CPP cell uptake include macropinocytosis and the clathrin and caveolae-dependent pathways. ${ }^{61,62}$ The most accepted cellular uptake mechanism of CPP is endocytosis. ${ }^{59}$ Positive charges mediate electrostatic interactions between the motifs of negatively charged lipids and sugars on the outer plasma membrane, thus promoting internalization. ${ }^{63}$ On the other hand, the internalization of nanoparticles mainly occurs through endocytosis. Consequently, most internalized cargos are trafficked to an endolysosomal compartment. ${ }^{64}$ However, endocytosis-mediated by receptor mechanisms cannot be discarded due to the interaction of the nanoparticles with proteins present in the culture medium to form the protein corona with certain proteins that favor recognition by the cellular receptors ${ }^{23}$ gathering the cell internalization.

Our results related to the interaction study by DLS and Langmuir isotherms supported that GNR-Arg ${ }_{7}$ CLPFFD enhanced liposomal interactions with respect to GNR-Arg and GNR-CLPFFD. The increased interaction with the cell 
membrane would favor subsequent internalization in the cell. However, further studies should be performed to study the cell penetration mechanism.

\section{Conclusion}

In conclusion, this study demonstrated that GNRs conjugation with oligoarginines and with amphipathic peptides, such as CLPFFD, results in enhanced biological membrane interactions. These interactions would be crucial to favor the further cell penetration. The conjugate GNR-Arg ${ }_{7} \mathrm{CLPFFD}$ does not affect the cell viability. Further experiments should be performed to analyze the cell penetration mechanism of GNR-Arg ${ }_{7}$ CLPFFD. Future prospective in vivo studies are required to establish its potential use for drug delivery.

\section{Acknowledgments}

This research was funded by Fondecyt Postdoctoral 3130654; FONDAP 15130011; Fondecyt 1170929, Fondecyt 1190623 , Nucleo UNAB 36/18N, CONACYT/CONICYT (México) 204393; CONICYT/CONACYT (Chile), and Fondequip EQM170111.

\section{Disclosure}

The authors report no conflicts of interest in this work.

\section{References}

1. Li M, Yang X, Ren J, Qu K, Qu X. Using graphene oxide high nearinfrared absorbance for photothermal treatment of Alzheimer's disease. Adv Mater. 2012;24(13):1722-1728. doi:10.1002/adma.201104864

2. Kong F-Y, Zhang J-W, Li R-F, Wang Z-X, Wang W-J, Wang W. Unique roles of gold nanoparticles in drug delivery, targeting and imaging applications. Molecules. 2017;22(9):1445.

3. Zhang N, Li S, Hua H, et al. Low density lipoprotein receptor targeted doxorubicin/DNA-gold nanorods as a chemo- and thermo-dual therapy for prostate cancer. Int J Pharm. 2016;513(1):376-386. doi:10.1016/j. ijpharm.2016.09.002

4. Farooq MU, Novosad V, Rozhkova EA, et al. Gold nanoparticles-enabled efficient dual delivery of anticancer therapeutics to hela cells. Sci Rep. 2018;8(1):2907. doi:10.1038/s41598-018-21331-y

5. Deshpande S, Sharma S, Koul V, Singh N. Core-shell nanoparticles as an efficient, sustained, and triggered drug-delivery system. ACS Omega. 2017;2(10):6455-6463. doi:10.1021/acsomega.7b01016

6. Efremova MV, Naumenko VA, Spasova M, et al. Magnetite-gold nanohybrids as ideal all-in-one platforms for theranostics. Sci Rep. 2018;8(1):11295. doi:10.1038/s41598-018-29618-w

7. Iqbal M, Usanase G, Oulmi K, et al. Preparation of gold nanoparticles and determination of their particles size via different methods. Mater Res Bull. 2016;79:97-104. doi:10.1016/j.materresbull.2015.12.026

8. Saha K, Agasti SS, Kim C, Li X, Rotello VM. Gold nanoparticles in chemical and biological sensing. Chem Rev. 2012;112(5):2739-2779. doi: $10.1021 / \mathrm{cr} 2001178$

9. DeLong RK, Reynolds CM, Malcolm Y, Schaeffer A, Severs T, Wanekaya A. Functionalized gold nanoparticles for the binding, stabilization, and delivery of therapeutic DNA, RNA, and other biological macromolecules. Nanotechnol Sci Appl. 2010;3:53-63. doi:10.2147/ NSA.S8984
10. Kogan MJ, Olmedo I, Hosta L, Guerrero A, Cruz LJ, Albericio F. Peptides and metallic nanoparticles for biomedical applications. Nanomedicine. 2007;2(3):287-306. doi:10.2217/17435889.2.3.287

11. Robson T, Shah DSH, Solovyova AS, Lakey JH. Modular protein engineering approach to the functionalization of gold nanoparticles for use in clinical diagnostics. ACS Appl Nano Mater. 2018;1 (7):3590-3599. doi:10.1021/acsanm.8b00737

12. Huang X, Neretina S, El-Sayed MA. Gold nanorods: from synthesis and properties to biological and biomedical applications. Adv Mater. 2009;21(48):4880-4910. doi:10.1002/adma.200802789

13. Link S, El-Sayed MA. Optical properties and ultrafast dynamics of metallic nanocrystals. Annu Rev Phys Chem. 2003;54(1):331-366. doi:10.1146/annurev.physchem.54.011002.103759

14. Alkilany AM, Murphy CJ. Toxicity and cellular uptake of gold nanoparticles: what we have learned so far? J Nanopart Res. 2010;12(7):2313-2333. doi:10.1007/s11051-010-9911-8

15. Pham T, Jackson JB, Halas NJ, Lee TR. Preparation and characterization of gold nanoshells coated with self-assembled monolayers. Langmuir. 2002;18(12):4915-4920. doi:10.1021/la015561y

16. Huang X, Jain PK, El-Sayed IH, El-Sayed MA. Plasmonic photothermal therapy (PPTT) using gold nanoparticles. Lasers Med Sci. 2007;23(3):217. doi:10.1007/s10103-007-0470-x

17. Araya E, Olmedo I, Bastus NG, et al. Gold nanoparticles and microwave irradiation inhibit beta-amyloid amyloidogenesis. Nanoscale Res Lett. 2008;3(11):435-443. doi:10.1007/s11671-008-9178-5

18. Li M, Guan Y, Zhao A, Ren J, Qu X. Using multifunctional peptide conjugated $\mathrm{Au}$ nanorods for monitoring $\beta$-amyloid aggregation and chemo-photothermal treatment of Alzheimer's disease. Theranostics. 2017;7(12):2996-3006. doi:10.7150/thno.18459

19. Kogan MJ, Bastus NG, Amigo R, et al. Nanoparticle-mediated local and remote manipulation of protein aggregation. Nano Lett. 2006;6 (1):110-115. doi:10.1021/n10516862

20. Soto C, Sigurdsson EM, Morelli L, Kumar RA, Castaño EM, Frangione B. $\beta$-sheet breaker peptides inhibit fibrillogenesis in a rat brain model of amyloidosis: implications for Alzheimer's therapy. Nat Med. 1998;4(7):822-826. doi:10.1038/nm0798-822

21. Adura C, Guerrero S, Salas E, et al. Stable conjugates of peptides with gold nanorods for biomedical applications with reduced effects on cell viability. ACS Appl Mater Interfaces. 2013;5(10):4076-4085. doi:10.1021/am3028537

22. Crouch PJ, Harding S-ME, White AR, Camakaris J, Bush AI, Masters CL. Mechanisms of $A \beta$ mediated neurodegeneration in Alzheimer's disease. Int J Biochem Cell Biol. 2008;40(2):181-198. doi:10.1016/j.biocel.2007.07.013

23. Prades R, Guerrero S, Araya E, et al. Delivery of gold nanoparticles to the brain by conjugation with a peptide that recognizes the transferrin receptor. Biomaterials. 2012;33(29):7194-7205. doi:10.1016/j. biomaterials.2012.06.063

24. Farkhani SM, Valizadeh A, Karami H, Mohammadi S, Sohrabi N, Badrzadeh F. Cell penetrating peptides: efficient vectors for delivery of nanoparticles, nanocarriers, therapeutic and diagnostic molecules. Peptides. 2014;57:78-94. doi:10.1016/j.peptides.2014.04.015

25. Zhang D, Wang J, Xu D. Cell-penetrating peptides as noninvasive transmembrane vectors for the development of novel multifunctional drug-delivery systems. J Controlled Release. 2016;229:130-139. doi:10.1016/j.jconrel.2016.03.020

26. Alhakamy NA, Dhar P, Berkland CJ. Charge type, charge spacing, and hydrophobicity of arginine-rich cell-penetrating peptides dictate gene transfection. Mol Pharm. 2016;13(3):1047-1057. doi:10.1021/ acs.molpharmaceut.5b00871

27. Pulido XC, Royo M, Albericio F, Rodríguez H. Péptidos que atraviesan la membrana celular como potenciales transportadores de fármacos. Bionatura. 2016;1(4):208-216.

28. MacCallum JL, Bennett WD, Tieleman DP. Transfer of arginine into lipid bilayers is nonadditive. Biophys $J$. 2011;101(1):110-117. doi:10. 1016/j.bpj.2011.05.038 
29. Schmidt N, Mishra A, Lai GH, Wong GC. Arginine-rich cell-penetrating peptides. FEBS Lett. 2010;584(9):1806-1813. doi:10.1016/j.febslet.2009.11.046

30. Velasco-Aguirre C, Morales F, Gallardo-Toledo E, et al. Peptides and proteins used to enhance gold nanoparticle delivery to the brain: preclinical approaches. Int J Nanomedicine. 2015;10:4919-4936. doi:10.2147/IJN.S82310

31. Sánchez-Navarro M, Giralt E, Teixidó M. Blood-brain barrier peptide shuttles. Curr Opin Chem Biol. 2017;38:134-140. doi:10.1016/j. cbpa.2017.04.019

32. Morshed RA, Muroski ME, Dai Q, et al. Cell-penetrating peptide-modified gold nanoparticles for the delivery of doxorubicin to brain metastatic breast cancer. Mol Pharm. 2016;13(6):1843-1854. doi:10.1021/acs.molpharmaceut.6b00004

33. Tong L, Cheng J-X. Gold nanorod-mediated photothermolysis induces apoptosis of macrophages via damage of mitochondria. Nanomedicine. 2009;4(3):265-276. doi:10.2217/nnm.09.4

34. Guerrero S, Herance JR, Rojas S, et al. Synthesis and in vivo evaluation of the biodistribution of a 18F-labeled conjugate gold-nanoparticle-peptide with potential biomedical application. Bioconjug Chem. 2012;23(3):399-408. doi:10.1021/bc200362a

35. Olmedo I, Araya E, Sanz F, et al. How changes in the sequence of the peptide CLPFFD-NH2 can modify the conjugation and stability of gold nanoparticles and their affinity for $\beta$-amyloid fibrils. Bioconjug Chem. 2008;19(6):1154-1163. doi:10.1021/bc800016y

36. Dynarowicz-Lạtka P, Dhanabalan A, Oliveira ON. A study on two-dimensional phase transitions in langmuir monolayers of a carboxylic acid with a symmetrical triphenylbenzene ring system. J Phys Chem B. 1999;103(29):5992-6000. doi:10.1021/jp9902102

37. Link S, El-Sayed M. Spectroscopic determination of the melting energy of a gold nanorod. $J$ Chem Phys. 2001;114(5):2362-2368. doi:10.1063/1.1336140

38. Rodríguez G, Rubio L, Barba C, et al. Characterization of new DOPC/DHPC platform for dermal applications. Eur Biophys $J$. 2013;42(5):333-345. doi:10.1007/s00249-012-0878-5

39. WL B. The diffraction of short electromagnetic waves by a crystal. Proc Camb Philol Soc. 1913;17:43-57.

40. Honeywell-Nguyen PL, Frederik PM, Bomans PH, Junginger HE, Bouwstra JA. Transdermal delivery of pergolide from surfactant-based elastic and rigid vesicles: characterization and in vitro transport studies. Pharm Res. 2002;19(7):991-997. doi:10.1023/A:1016466406176

41. Amani H, Arzaghi H, Bayandori M, et al. Controlling cell behavior through the design of biomaterial surfaces: a focus on surface modification techniques. Adv Mat Interf. 2019;6(13):1900572. doi:10.10 02/admi.v6.13

42. Tielens F, Santos E. AuS and SH bond formation/breaking during the formation of alkanethiol SAMs on $\mathrm{Au}(111)$ : a theoretical study. J Phys Chem C. 2010;114(20):9444-9452. doi:10.1021/jp102036r

43. Liu H, Pierre-Pierre N, Huo Q. Dynamic light scattering for gold nanorod size characterization and study of nanorod-protein interactions. Gold Bull. 2012;45(4):187-195. doi:10.1007/s13404-0120067-4

44. Murphy CJ, Thompson LB, Alkilany AM, et al. The many faces of gold nanorods. J Phys Chem Lett. 2010;1(19):2867-2875. doi:10.10 21/jz100992x

45. Van Meer G, Voelker DR, Feigenson GW. Membrane lipids: where they are and how they behave. Nature Rev Mol Cell Biol. 2008;9 (2):112-124. doi:10.1038/nrm2330

46. Tashima $\mathrm{T}$. Intelligent substance delivery into cells using cell-penetrating peptides. Bioorg Med Chem Lett. 2017;27(2):121-13 0. doi:10.1016/j.bmcl.2016.11.083

47. Broniatowski M, Sandez Macho I, Minones J, Dynarowicz-Latka P. Langmuir monolayers characteristic of (perfluorodecyl)-alkanes. J Phys Chem B. 2004;108(35):13403-13411. doi:10.1021/jp0402481
48. Parra-Barraza H, Burboa MG, Sánchez-Vázquez M, Juárez J, Goycoolea FM, Valdez MA. Chitosan-cholesterol and chitosan-stearic acid interactions at the air-water interface. Biomacromolecules. 2005;6(5):2416-2426. doi:10.1021/bm050106s

49. López-Oyama AB, Flores-Vázquez AL, Burboa MG, GutiérrezMillán LE, Ruiz-García J, Valdez MA. Interaction of the cationic peptide bactenecin with phospholipid monolayers at the air-water interface: I interaction with 1,2-dipalmitoyl-sn-glycero-3-phosphatidilcholine. J Phys Chem B. 2009;113(29):9802-9810. doi:10.1021/ jp902709t

50. Valencia-Rivera DE, Básaca-Loya A, Burboa MG, et al. Interaction of $\mathrm{N}$-nitrosodiethylamine/bovine serum albumin complexes with 1,2-dipalmitoyl-sn-glycero-3-phosphocholine monolayers at the airwater interface. J Colloid Interface Sci. 2007;316(2):238-249. doi:10.1016/j.jcis.2007.07.079

51. Otto F, Brezesinski G, van Hoogevest P, Neubert RHH. Physicochemical characterization of natural phospholipid excipients with varying PC content. Colloids Surf A. 2018;558:291-296. doi:10.1016/j.colsurfa.2018.08.037

52. Lönnroth E-C. Toxicity of medical glove materials: a pilot study. Int J Occup Safety Ergon. 2005;11(2):131-139. doi:10.1080/1080 3548.2005.11076642

53. Morales-Zavala F, Casanova-Morales N, Gonzalez RB, et al. Functionalization of stable fluorescent nanodiamonds towards reliable detection of biomarkers for Alzheimer's disease. J Nanobiotechnology. 2018;16(1):60. doi:10.1186/s12951-018-0385-7

54. Maiolo JR, Ferrer M, Ottinger EA. Effects of cargo molecules on the cellular uptake of arginine-rich cell-penetrating peptides. Biochimica Biophys Acta (BBA)-Biomembr. 2005;1712(2):161-172. doi:10.1016/ j.bbamem.2005.04.010

55. Chen Y-J, Liu BR, Dai Y-H, et al. A gene delivery system for insect cells mediated by arginine-rich cell-penetrating peptides. Gene. 2012;493(2):201-210. doi:10.1016/j.gene.2011.11.060

56. Takayama K, Hirose H, Tanaka G, et al. Effect of the attachment of a penetration accelerating sequence and the influence of hydrophobicity on octaarginine-mediated intracellular delivery. Mol Pharm. 2012;9(5):1222-1230. doi:10.1021/mp200518n

57. Tünnemann G, Cardoso MC, Castanho M. Cell-penetrating peptides —uptake, toxicity, and applications. Membr Active Pept. 2009;9:329.

58. Amani H, Habibey R, Shokri F, et al. Selenium nanoparticles for targeted stroke therapy through modulation of inflammatory and metabolic signaling. Sci Rep. 2019;9(1):6044. doi:10.1038/s41598019-42633-9

59. Pujals S, Fernández-Carneado J, López-Iglesias C, Kogan MJ, Giralt E. Mechanistic aspects of CPP-mediated intracellular drug delivery: relevance of CPP self-assembly. Biochimica Biophys Acta (BBA)-Biomembr. 2006;1758(3):264-279. doi:10.1016/j.bbamem.20 06.01 .006

60. Takeuchi T, Futaki S. Current understanding of direct translocation of arginine-rich cell-penetrating peptides and its internalization mechanisms. Chem Pharm Bulletin. 2016;64(10):1431-1437. doi:10. 1248/cpb.c16-00505

61. Räägel H, Säälik P, Pooga M. Peptide-mediated protein deliveryWhich pathways are penetrable? Biochimica Biophys Acta (BBA)Biomembr. 2010;1798(12):2240-2248. doi:10.1016/j.bbamem.2010. 02.013

62. Guidotti G, Brambilla L, Rossi D. Cell-penetrating peptides: from basic research to clinics. Trends Pharmacol Sci. 2017;38(4):406-424. doi:10.1016/j.tips.2017.01.003

63. Verdurmen WP, Brock R. Biological responses towards cationic peptides and drug carriers. Trends Pharmacol Sci. 2011;32(2):116-124. doi:10.1016/j.tips.2010.11.005

64. Lundin P, Johansson H, Guterstam P, et al. Distinct uptake routes of cell-penetrating peptide conjugates. Bioconjug Chem. 2008;19 (12):2535-2542. doi:10.1021/bc800212j 


\section{Publish your work in this journal}

The International Journal of Nanomedicine is an international, peerreviewed journal focusing on the application of nanotechnology in diagnostics, therapeutics, and drug delivery systems throughout the biomedical field. This journal is indexed on PubMed Central, MedLine, CAS, SciSearch ${ }^{\mathbb{B}}$, Current Contents ${ }^{\mathbb{B}} /$ Clinical Medicine,
Journal Citation Reports/Science Edition, EMBase, Scopus and the Elsevier Bibliographic databases. The manuscript management system is completely online and includes a very quick and fair peer-review system, which is all easy to use. Visit http://www.dovepress.com/ testimonials.php to read real quotes from published authors. 